\title{
Hybrid Neural Network Controller Design For a Batch Reactor to Produce Methyl Methacrylate
}

\author{
Paisan Kittisupakorn $^{1, \mathrm{a}}$, Thanutchaporn Charoenniyom ${ }^{1}$, and Wachira Daosud ${ }^{2, \mathrm{~b}}$ \\ 1 Department of Chemical Engineering, Faculty of Engineering, Chulalongkorn University, Patumwan, \\ Bangkok, 10330, Thailand \\ 2 Department of Chemical Engineering, Faculty of Engineering, Burapha University, Chonburi 20131, \\ Thailand \\ E-mail: apaisan.k@chula.ac.th, bwachira@buu.ac.th (Corresponding author)
}

\begin{abstract}
Methyl methacrylate (MMA) production in an exothermic batch reactor provides a challenging problem for studying its dynamics behavior and temperature control. This work presents a neural network forward model (NN) to predict a concentration of methyl methacrylate, a jacket temperature and temperature profile in the reactor. An optimal NN model has been employed to predict state variables incorporating into a model predictive control (MPC) algorithm to determine optimal control actions. To control the temperature, neural network based control approaches: a neural network direct inverse control (NNDIC) and a neural network based model predictive control (NNMPC) have been formulated. In addition, a dynamic optimization approach has been applied to find out an optimal operating temperature to achieve maximizing the MMA product at specified final time. The robustness of the proposed control strategy is investigated with respect to changes in operating parameters: rate of reaction, heat of reaction and overall heat transfer coefficient. Simulation results have indicated that the NNMPC is robust and gives the best control results among the PID and NNDIC in all cases.
\end{abstract}

Keywords: Methyl methacrylate, batch reactor, neural network based model predictive control, neural network direct inverse control, dynamic optimization.

ENGINEERING JOURNAL Volume 18 Issue 1

Received 18 June 2013

Accepted 15 October 2013

Published 14 January 2014

Online at http://www.engj.org/

DOI:10.4186/ ej.2014.18.1.145 


\section{Introduction}

Methyl methacrylate (MMA), which is used to produce polymethyl methacrylate (acrylic plastics) and polymer dispersions, is an important chemical polymer intermediate. The world production capacity has been double increased in past 15 years and the MMA demand is still expected growth in the future [1]. The MMA can be manufactured by many routes. An esterification of mathacrylic acid with methanol in a batch reactor is a successful route on account of achieving the maximum yield. In a batch reactor with exothermic reactions, the heat-released of reactions in heating period may become very large very quickly and the heat-generated can exceed the cooling capacity of the reactor and then runaway reactions take place [2-3]. To overcome the problem, model based control strategies have been proposed to solve the problem [4-7]. However, control performances of such control strategies rely upon the accuracy of mathematical models developed.

To overcome the problem, neural networks studied and provided successfully to capture the dynamics of nonlinear and complex systems have been proposed and formulated [8-13]. Neural networks have several advantages of distributed information processing and the inherent potential for parallel computation. The potential for the processing and approximation relates to operating data without the prior knowledge of the process. They can learn adequately accurate models and give good non-linear control when model equations are not known or only partial state information is available. Neural networks can be employed to be mathematical model, estimator and controller. Kittisupakorn et al. [14] demonstrated dynamic neural network modeling for hydrochloric acid recovery acid process to predict the concentration profile of a hydrochloric acid recovery process consisting of double fixed-bed ion exchange columns. Rusinowski and Stanek [15] presented a method and example results of calculations of neural modeling of steam boilers. Charoenniyom et al. [16] applied neural network to be a modeling for the methyl methacrylate production process in a batch reactor and Thampasato et al. [17] proposed neural network modeling for a batch crystallizer. For the process control, Nueaklong et al. [18] investigated neural network modeling for hard chrome electroplating process to predict the plating solution temperature in hard chrome electroplating bath and applied the neural network inverse model as a controller for controlling plating solution temperature to the desired temperature range. Daosud et al. [19] presented the neural network for inverse model to be a controller for a steel pickling process. Kittisupakorn et al. [20] presented a multi-layer feedforward neural network based model predictive control for a steel pickling process. The neural network for forward model is applied as mathematical model to predict the state variables in the model predictive control algorithm. For use the neural network as an estimator, Arpornwichanop and Shomchoam [21] applied neural network as an estimator to estimate the unmeasured state variables for fed-batch bioreactors.

The goal of this paper is to provide an effective control technique to control the system. To achieve this, this paper has developed the neural network forward model to predict the dynamics behavior and the neural network inverse model to control the process integrated with the dynamic optimization. Both neural network forward and inverse models have been developed based on the Lenvenberg-Marquardt training algorithm. An optimal neural network structures for forward and inverse models are chosen based on mean square error (MSE). The obtained optimal neural network structure for forward model has been employed to predict state variables over a predictive horizon within a model predictive control (MPC) algorithm for searching optimal control actions via successive quadratic programming (SQP). Robustness tests of the proposed controls have been studied with respect to changes in operating parameters.

\section{Mathematical Models for Methyl Methacrylate Production Process in a Batch Reactor}

Mathematical models for esterification reaction of a methyl methacrylate in a batch reactor studied in this work have been developed. The esterification reaction involved in this study is given below.

$$
\mathrm{CH}_{2}=\mathrm{C}\left(\mathrm{CH}_{3}\right)-\mathrm{COOH}+\mathrm{CH}_{3} \mathrm{OH} \leftrightarrow \mathrm{CH}_{2}=\mathrm{C}\left(\mathrm{CH}_{3}\right)-\mathrm{COOCH}_{3}+\mathrm{H}_{2} \mathrm{O}
$$

It is assumed that the kinetic equation of the esterification reaction of methacrylic acid with methanol is reversible and the reaction takes place in liquid phase. From Witczak et al. [22], the reaction rate constants for this reaction are described by the following equations. 


$$
\begin{gathered}
R_{A}=k_{1} C_{c a t} \frac{C_{A} C_{B}}{C_{C}^{0.3}}-k_{2} C_{c a t} C_{C}^{0.7} C_{D} \\
k_{1}=960 \exp \left(-\frac{63,600}{R T_{r}}\right) \\
k_{2}=600 \exp \left(-\frac{67,320}{R T_{r}}\right)
\end{gathered}
$$

where $C_{A}, C_{B}, C_{C}, C_{D}$ and $C_{c a t}$ refer to concentration of methacrylic acid, methanol, methyl methacrylate, water and catalyst in $\mathrm{mol} / \mathrm{m}^{3}$, respectively.

The mass and the energy balances described the change of each component and temperatures are:

$$
\begin{gathered}
\frac{d C_{A}}{d t}=-R_{A} \\
\frac{d C_{B}}{d t}=-R_{A} \\
\frac{d C_{C}}{d t}=R_{A} \\
\frac{d C_{D}}{d t}=R_{A} \\
\frac{d T_{r}}{d t}=\frac{Q_{r}+Q_{j}}{C_{r} C p_{r}} \\
\frac{F_{j} p_{j} C p_{r}\left(T_{j s p^{-}} T_{j}\right)-Q_{j}}{V_{j} p_{j} C p_{j}} \\
C p_{r}=\frac{C p_{A} C_{A}+C p_{B} C_{B}+C p_{C} C_{C}+C p_{D} C_{D}}{C_{A}+C_{B}+C_{C}+C_{D}} \\
Q_{j}=U A\left(T_{j}-T_{r}\right)
\end{gathered}
$$

where $\mathrm{Q}, \Delta \mathrm{H}$ and $\mathrm{U}$ are heat released from reaction $(\mathrm{kJ} / \mathrm{min})$, heat of reaction $(\mathrm{kJ} / \mathrm{kmol})$ and heat transfer coefficient $\left(\mathrm{kJ} /\left(\min \mathrm{m}^{2}{ }^{\circ} \mathrm{C}\right)\right)$, respectively.

\section{Neural Network Modeling}

Neural networks consist of an input layer, hidden layer(s) and an output layer with each layer composing of a processing unit. The input layer receives the external inputs from the outside of the network. The output layer will produce the output of the network according to the input data sets. In the hidden layers, the value from each input neuron is multiplied by a weight and is calculated by transfer function. 
In this part, neural network forward model is applied to predict the dynamic behavior of the system. The training, testing and validating data sets for neural network modeling are generated from the first principle mathematical model covering several possible scenarios consisting of nominal and plant uncertainty cases. Rate of reaction, heat of reaction and overall heat transfer coefficient are considered as plant/model mismatches. In addition, the manipulated variable (the set point of the jacket temperature) is adjusted as step change and random change.

Table 1. Physical properties simulation system geometric characteristics.

\begin{tabular}{lr}
\hline Heat capacity of methacrylic acid $(\mathrm{J} / \mathrm{mol} \mathrm{K})$ & 167.817 \\
Heat capacity of methanol $(\mathrm{J} / \mathrm{mol} \mathrm{K})$ & 81.080 \\
Heat capacity of methyl methacrylate $(\mathrm{J} / \mathrm{mol} \mathrm{K})$ & 191.202 \\
Heat capacity of water $(\mathrm{J} / \mathrm{mol} \mathrm{K})$ & 1000 \\
Heat capacity of water in jacket $(\mathrm{J} / \mathrm{mol} \mathrm{K})$ & 1000 \\
Density of methacrylic acid $\left(\mathrm{kg} / \mathrm{m}^{3}\right)$ & 1015 \\
Density of methanol $\left(\mathrm{kg} / \mathrm{m}^{3}\right)$ & 791.8 \\
Density of methyl methacrylate $\left(\mathrm{kg} / \mathrm{m}^{3}\right)$ & 940 \\
Density of water $\left(\mathrm{kg} / \mathrm{m}^{3}\right)$ & 1000 \\
Density of water in jacket $\left(\mathrm{kg} / \mathrm{m}^{3}\right)$ & 1000 \\
Heat of reaction $(\mathrm{J} / \mathrm{mol})$ & -57500 \\
Molecular weight of methacrylic acid $(\mathrm{kg} / \mathrm{kmol})$ & 86.08 \\
Molecular weight of methanol $(\mathrm{kg} / \mathrm{kmol})$ & 32.04 \\
Molecular weight of methyl methacrylate $(\mathrm{kg} / \mathrm{kmol})$ & 100.12 \\
Molecular weight of water $(\mathrm{kg} / \mathrm{kmol})$ & 18.00 \\
Volume of reactor $(\mathrm{m})$ & 0.0025 \\
Overall heat transfer coefficient $\left(\mathrm{J} / \mathrm{sec} \mathrm{m}^{2} \mathrm{~K}\right)$ & 274.42 \\
Area of jacket $\left(\mathrm{m}^{2}\right)$ & 0.05 \\
Volume of jacket $\left(\mathrm{m}^{3}\right)$ & 0.001 \\
Gas constant $\left(\mathrm{kJ} / \mathrm{kmol} \mathrm{K}^{3}\right)$ & 8.314 \\
Flow rate of jacket $\left(\mathrm{m}^{3} / \mathrm{sec}\right)$ & $3.5 \times 10^{-5}$ \\
\hline
\end{tabular}

After that, all generated data subsets are integrated to one overall set consisting of 4,500 patterns and the pattern in the overall set is randomized. The obtained data set are classified into 3 sets consisting of $60 \%, 30 \%$ and $10 \%$ of the obtained total data as a training, testing and validating data set, respectively. The number of samples for training, testing and validating data sets are shown in Table 2.

The generated data requires normalization for achieving a good performance neural network modeling. In the normalization step, all data were scaled in range of minimum and maximum value. The minimum and maximum data were compared to 0.05 and 0.95 , respectively. The equations for data normalization and converting back can be expressed as follows:

$$
\begin{gathered}
x_{n o r}=\frac{\left(x-x_{\min }\right)(0.95-0.05)}{\left(x_{\max }-x_{\min )}\right.}+0.05 \\
x=\frac{\left(x_{\text {nor }}-0.05\right)\left(x_{\max }-x_{\min }\right)}{(0.95-0.05)}+x_{\min }
\end{gathered}
$$

where $\mathrm{x}$ and $\mathrm{x}_{\mathrm{nor}}$ are the actual and normalized values, respectively.

In the training step, the Levenberg Marquardt algorithm is used to train the both neural network models. During the training, the neural network adjusts the weights and biases in each node connection but there does not adjust during the testing and validating to evaluate the neural network performance. The structure for the neural network forward model consists of 8 nodes in an input layer and 3 nodes in an output layer as shown in Fig. 1. The input layer nodes are composed of the past and present values of the reactor temperature, the concentration of methyl methacrylate, the jacket temperature and the set point of 
the jacket temperature. The output layer nodes are the future values of the reactor temperature, the jacket temperature and the concentration of methyl methacrylate.

\begin{tabular}{|c|c|c|}
\hline $\mathrm{C}_{\mathrm{C}}(\mathrm{k}-1)$ & $\mathrm{C}_{\mathrm{C}}(\mathrm{k})$ & $\mathrm{C}_{\mathrm{C}}(\mathrm{k}+1)$ \\
\hline $\mathrm{T}_{\mathrm{r}}(\mathrm{k}-1)$ & $\mathrm{T}_{\mathrm{r}}(\mathrm{k})$ & $\mathrm{T}_{\mathrm{r}}(\mathrm{k}+1)$ \\
\hline $\mathrm{T}_{\mathrm{j}}(\mathrm{k}-1)$ & $\mathrm{T}_{\mathrm{j}}(\mathrm{k})$ & $\mathrm{T}_{\mathrm{j}}(\mathrm{k}+1)$ \\
\hline $\mathrm{T}_{\text {jsp }}(\mathrm{k}-1)$ & $\mathrm{T}_{\text {jsp }}(\mathrm{k})$ & \multicolumn{1}{|c}{} \\
\cline { 1 - 2 } & &
\end{tabular}

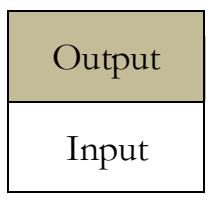

Fig. 1. Input/output pattern for the forward model.

In the neural network design step, the appropriated neural network structure is defined by choosing the number of nodes in the hidden layer. Both neural network forward and inverse models have been developed based on the Lenvenberg-Marquardt training algorithm. The sigmoid function is used as the activation function of the nodes in the hidden layer and the linear transfer function is used as the activation function in its output layer. A common objective of the neural network training is to minimize an error between predicted neural network values and actual targeted values. An equation for MSE calculation is shown below:

$$
M S E=\frac{1}{n} \sum_{i=1}^{n}\left(T_{a c i}-T_{p i}\right)^{2}
$$

where $T_{a c}$ is the actual targeted values and $T_{p}$ is the predicted neural network values.

After training step, the trained neural network model is tested with testing data sets. If the MSE values of the testing data are out of a specified value, the obtained neural network model is inapplicable and more training is required by reinitialize the weights and biases. Alternatively, another neural network structure is considered. On the other hand, if the MSE values of the testing data sets are satisfied, the obtained neural network model is validated by validating data set. If the MSE values of validating set are not out of a specified value, the network structure is changed by changing the number of hidden layers and the number of nodes in the hidden layer. In this paper, the number of hidden layer is varied from 1 node to 20 nodes.

Basic steps of the neural network designing are shown in Fig. 2. Many procedures of the neural network designing are summarized in this figure.

Table 2. The MSE of the testing and validation sets of forward and inverse models.

\begin{tabular}{lccc}
\hline \multicolumn{1}{c}{ Data sets } & Forward model (MSE) & Inverse model (MSE) & No. of samples \\
\hline Training & $4.6068 \times 10^{-5}$ & $3.6992 \times 10^{-5}$ & 2700 \\
Testing set 1 & $3.5618 \times 10^{-5}$ & $2.0184 \times 10^{-5}$ & 675 \\
Testing set 2 & $3.1400 \times 10^{-5}$ & $1.0795 \times 10^{-5}$ & 675 \\
Validating set & $5.0784 \times 10^{-5}$ & $2.0489 \times 10^{-5}$ & 450 \\
\hline
\end{tabular}

\section{Neural Network Direct Inverse Control (NNDIC)}

In this part, a neural network inverse model is applied to formulate a neural network direct inverse controller to control the process. The detailed procedures to find the inverse neural network model are summarized in the Fig. 2. A neural network inverse model structure consists of 8 nodes in an input layer and a node in an output layer.

An optimal neural network inverse model is utilized to predict a manipulated variable (a set point of a jacket temperature). The neural network inverse model for the set point of the jacket temperature prediction requires the past and present values of the process outputs and the past values of manipulated variable and the set point of the reactor temperature. The input and output patterns for the neural network inverse model is shown in Fig. 3. 


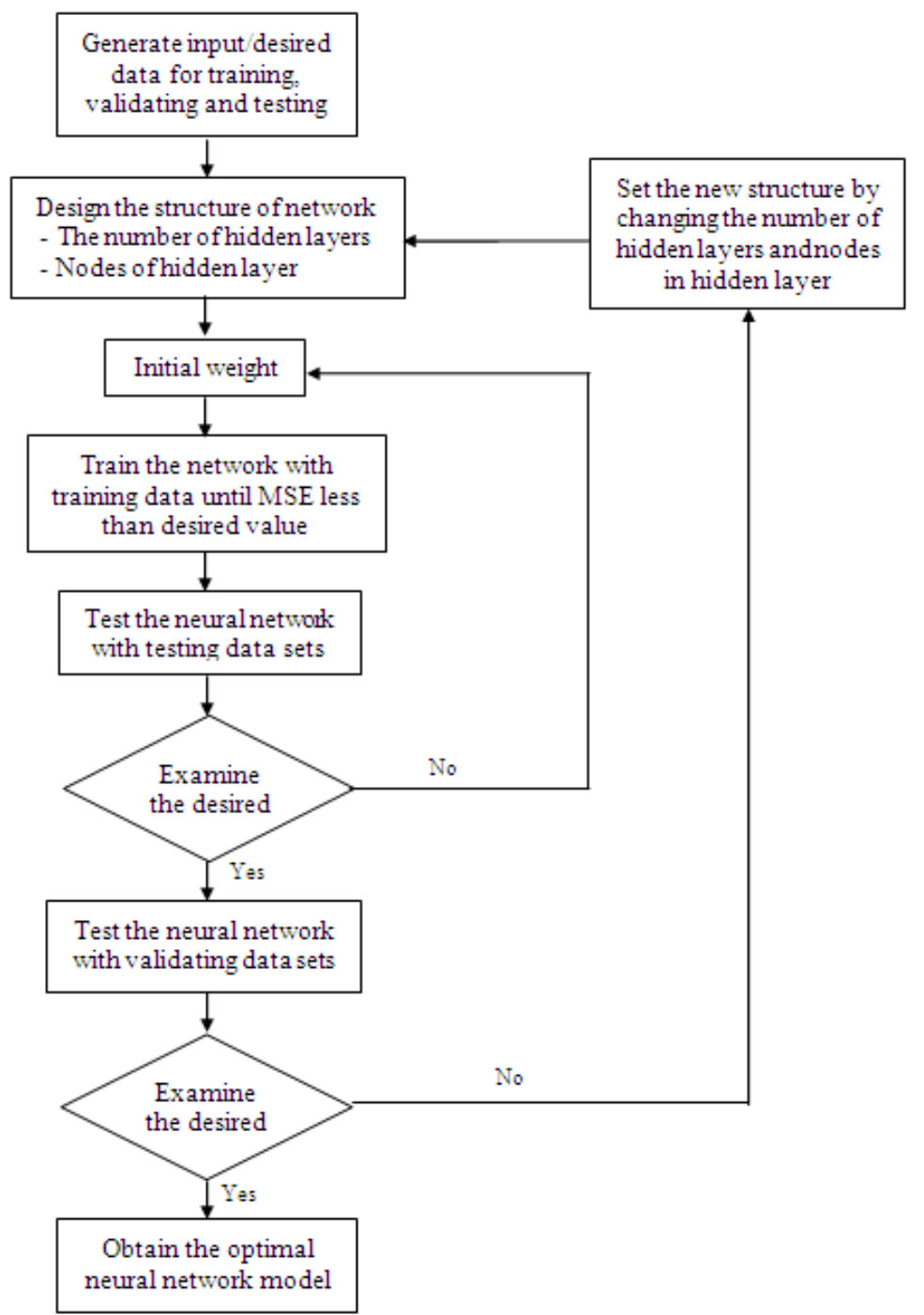

Fig. 2. Procedures of the neural network designing.

\begin{tabular}{|c|c|c|c|}
\hline $\mathrm{C}_{\mathrm{C}}(\mathrm{k}-1)$ & $\mathrm{C}_{\mathrm{C}}(\mathrm{k})$ & & Output \\
\hline $\mathrm{T}_{\mathrm{r}}(\mathrm{k}-1)$ & $\mathrm{T}_{\mathrm{r}}(\mathrm{k})$ & $\mathrm{T}_{\mathrm{r}}(\mathrm{k}+1)$ & Input \\
\hline $\mathrm{T}_{\text {jsp }}(\mathrm{k}-1)$ & $\mathrm{T}_{\text {jsp }}(\mathrm{k})$ & & \\
\hline $\mathrm{T}_{\mathrm{j}}(\mathrm{k}-1)$ & $\mathrm{T}_{\mathrm{j}}(\mathrm{k})$ & & \\
\hline
\end{tabular}

Fig. 3. Input/output patterns for the inverse model.

The NNDIC strategy for controlling the temperature is shown in Fig. 4. The control performance is tested under the uncertainly of the process including changes of kinetic rate, heat of reactions and heat transfer coefficient. 


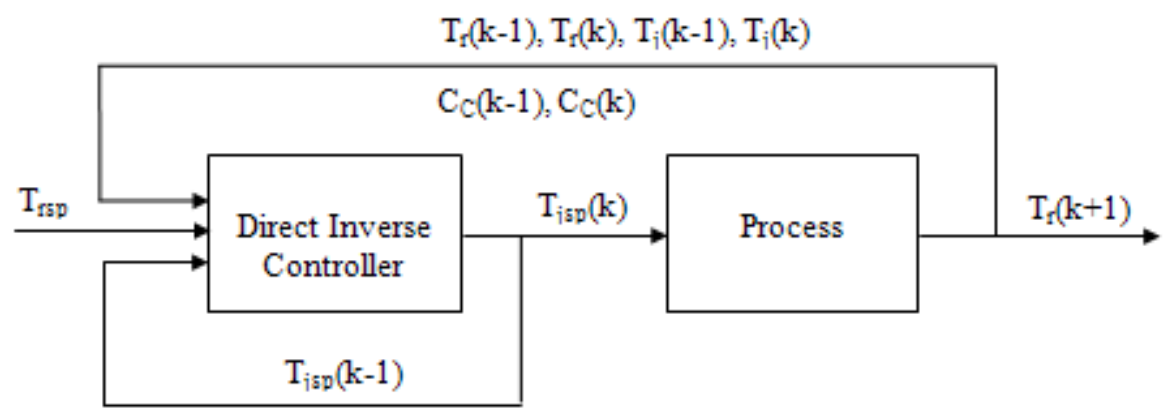

Fig. 4. The structure of NNDIC strategy.

\section{Dynamic Optimization}

The goal of a dynamic optimization problem is to find an optimal control profile of one or more control variables or control parameters of a system. Optimality is defined as a minimization or maximization of an objective function without violating given the process constraints [23-24]. In this work, a program is written to solve the optimization problem using a sequential quadratic programming (SQP) algorithm in Matlab Optimization Toolbox. The written program is tested to determine an optimal temperature of the exothermic batch reactor studied by Aziz et al. [25].

In this work, an objective is to determine the optimal temperature policy maximizing the amount of a desired product concentration for a given fixed batch time subject to bounds on the reactor temperature. The problem can be written mathematically as:

$$
\max _{T_{r}} C_{c}\left(t_{f}\right)
$$

Subject to

$$
\begin{array}{ll}
\dot{x}=f\left(x(t), T_{r}, p, t\right) & \text { process model } \\
x\left(t_{o}\right)=x(o) & \text { initial condition } \\
298 K \leq T_{r} \leq 348 K & \text { boundary condition } \\
t_{f}=t_{f}^{*} &
\end{array}
$$

where $x$ is the vector of state variables, $\dot{x}$ is the derivative of $x$ with respect to time $(t)$ and $p$ is the process parameters. The batch time $\left(t_{f}\right)$ is specified at 10 hours. The lower bound on the temperature is the initial temperature that operates at the ambient condition and the upper bound is dictated by the maximum temperature of the experimental data used by Witczak et al. [22].

\section{Neural Network Based Model Predictive Control (NNMPC)}

MPC appears to be one of general approaches which can handle most common process characteristics and industrial requirements in a satisfactory way [26-27]. The key success factor in the use of MPC in these process problems is the existence of accurate process models. [28-29] Then, the obtained neural network forward model in the neural network modeling part is applied as a predictor to predict the future values of outputs over a prediction horizon $(p)$ within a model predictive control algorithm. An optimal manipulated variable $\left(T_{\text {isp }}\right)$ is determined by solving the optimization problem to minimize a specified objective function subject to the neural network model and lower and upper bounds of the manipulated variable (a set point of a jacket temperature). Figure 5 illustrates the structure of a neural network model predictive control (NNMPC) strategy. A program is used to solve the optimization problem using a successive quadratic programming (SQP) algorithm. The optimization problem is shown below:

$$
\min _{T_{j s p}} \sum_{i=1}^{p}\left[W_{1}\left\{T_{r}(k+i)-T_{r s p}(k+i)\right\}^{2}+W_{2}\left\{\Delta T_{j s p}(k+i)\right\}^{2}\right]
$$


Subject to

$$
\begin{aligned}
& \text { Neural network forward model } \\
& 260 \mathrm{~K} \leq \mathrm{T}_{\mathrm{jsp}}(\mathrm{k}+1) \leq 380 \mathrm{~K}, \mathrm{i}=1,2,3, \ldots, \mathrm{P} \\
& \mathrm{T}_{\mathrm{r}}(\mathrm{k}+\mathrm{p})=\mathrm{T}_{\mathrm{rsp}}(\mathrm{k}+\mathrm{p})
\end{aligned}
$$

where $\mathrm{p}$ is a parameter specifying the prediction horizon, $\mathrm{M}$ is the control horizon, $\mathrm{W}_{\mathrm{i}}$ is the weighting parameter used to give different weights to different squared tracking error and $T_{\text {rsp }}$ is the set point of the reactor temperature obtained off-line optimization.

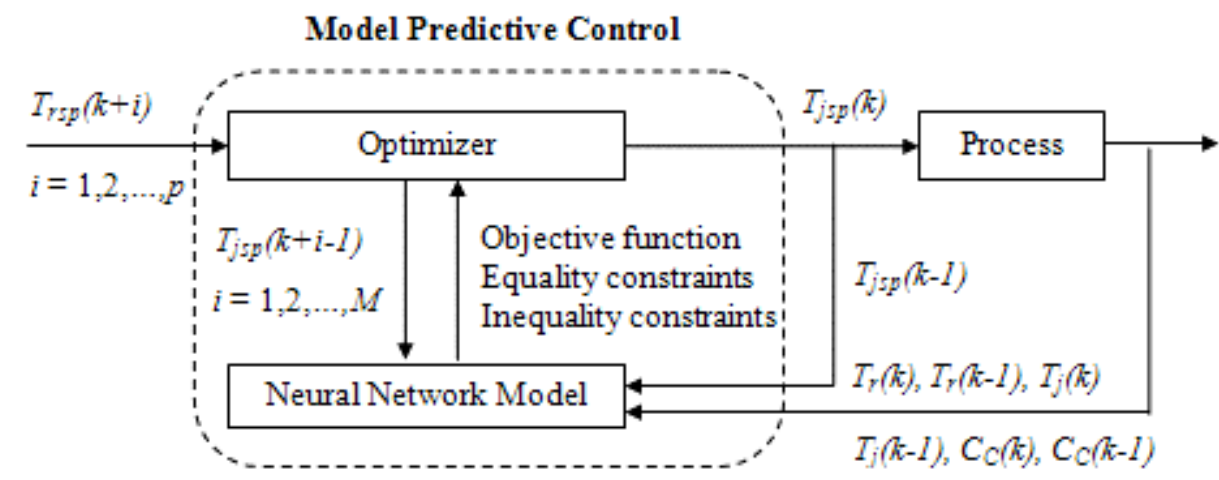

Fig. 5. The NNMPC strategy.

\section{Simulation Results}

\subsection{Neural Network Forward and Inverse Models}

After training the neural network models, the neural network forward and inverse models are validated by the sets of validating data for the performance monitoring. Optimal structures for the forward and inverse models are [8-6-8-3] and [8-4-8-1] respectively and their MSEs for the testing and validating sets are presented in the Table 2. This table shows that the neural network forward model can predict the values of the concentration of MMA, the jacket temperature and the reactor temperature with great accuracy and the neural network inverse model gives good prediction of the set point of jacket temperature.

\subsection{Dynamic Optimization}

The dynamic optimization maximizing production concentration with respect to variations of time intervals: 1, 2, 4 and 8 intervals have been carried out. The simulation results with different time intervals are shown in Fig. 6. Table 3 reports the temperature and the concentration of MMA (desire product) of each time intervals. It has been found that at the final time, the maximum product achieves at the case of 8 intervals. The obtained optimal temperature profile is then applied as set points of the reactor temperature for control design.

Table 3. Optimization results

\begin{tabular}{llr}
\hline Interval & \multicolumn{1}{c}{ Off-line optimal temperature (K) } & $\mathbf{C}_{\mathbf{C}}\left(\boldsymbol{t}_{\boldsymbol{t}}\right)$ \\
\hline 1 & 342.45 & 13.932 \\
2 & $348.00,329.77$ & 13.949 \\
4 & $348.00,347.98,336.32,325.21$ & 13.952 \\
8 & $348.00,348.00,347.47,345.88,341.60,333.48,328.15,324.84$ & 13.962 \\
\hline
\end{tabular}




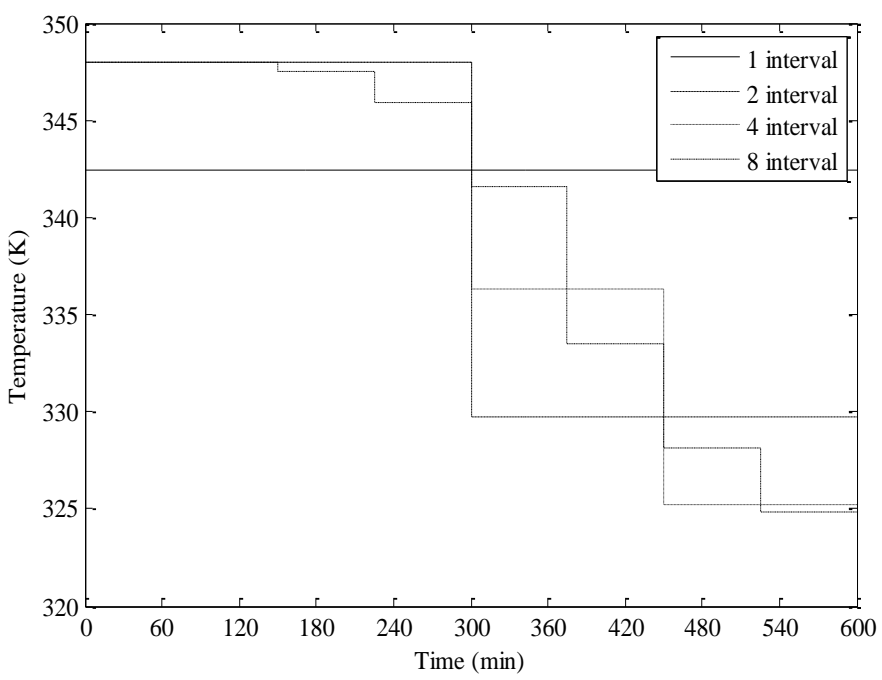

Fig. 6. Temperature profile for the optimization problem.

\subsection{Neural Network Model Based Control}

For this case, the controllers are adjusted with the same IAE for the same control performance. The objective of the control is to control the reactor temperature to the desired set point by adjusting the set point of a jacket temperature. The controlled simulations are divided into two cases which are nominal case and plant/model mismatch case. The conditions of the mismatch case are defined by $30 \%$ increasing and $30 \%$ decreasing of the model parameter values from the nominal condition (Table 1., Eq. (2) and Eq (3)) such as $\mathrm{k}_{1}, \mathrm{k}_{2}, \Delta \mathrm{H}$ and $\mathrm{U}$. The closed-loop performance of the NNMPC, the NNDIC and the PID control are indicated by the integral of absolute value of an error (IAE).

The simulation results of the nominal case with the process parameters presented in Table 1 indicate that the NNMPC can bring the temperature closely to the set point without overshoot, oscillations and offset as show in Fig. 7. In contrast, the NNDIC and the PID control cause the overshoot and oscillation of the control variable (reactor temperature) as show in Fig. 8 and 9, respectively. Moreover, the dynamic behavior of NNMPC manipulated variable is smoother than the NNDIC and the PID control.

For the plant/model mismatch cases, a rate of reaction for forward reaction, a rate reaction for reverse reaction, a heat of reaction and an overall heat transfer coefficient are considered as the plant/model mismatch parameters because these parameters are prone to errors in the real process. Then the model mismatch cases are divided into 6 cases as follows

- $30 \%$ increasing of $\mathrm{k}_{1}$ case

- $30 \%$ decreasing of $\mathrm{k}_{2}$ case

- $30 \%$ increasing of $\mathrm{k}_{1}$ and $30 \%$ decreasing of $\mathrm{k}_{2}$ case

- $30 \%$ increasing of $\Delta \mathrm{H}$ case

- $30 \%$ decreasing of $\mathrm{U}$ case

- $30 \%$ increasing of $\mathrm{k}_{1}, 30 \%$ decreasing of $\mathrm{k}_{2}, 30 \%$ increasing of $\Delta \mathrm{H}$ and $30 \%$ decreasing of $\mathrm{U}$ case

The simulation results in the case of the decrease in U of 30\% for the NNMPC, PID and NNDIC are shown in Fig. 10, 11 and 12, respectively. These figures illustrate that the NNMPC strategy can bring the reactor temperature to the set point by gradually adjusting the jacket temperature set point which then gives smooth control response. The NNDIC and PID, on the other hand, can control the reactor temperature to the set point but with drastic adjustment of the jacket temperature set point causing the oscillation and overshoot in the process response. For the control comparison, the NNMPC give the best control performance in all parameter mismatch cases and the NNDIC is more robust than PID control. The performance index in term of the absolute error (IAE) of three different controllers in nominal case and parameter mismatch cases are summarized in Table 4. 


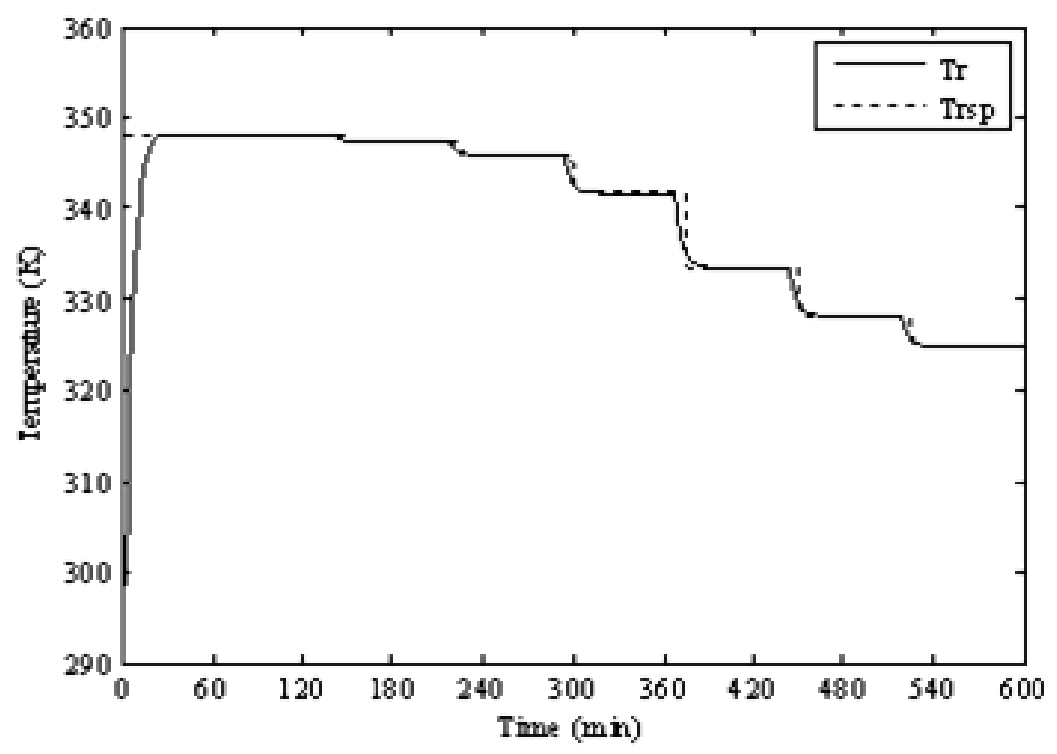

(a)

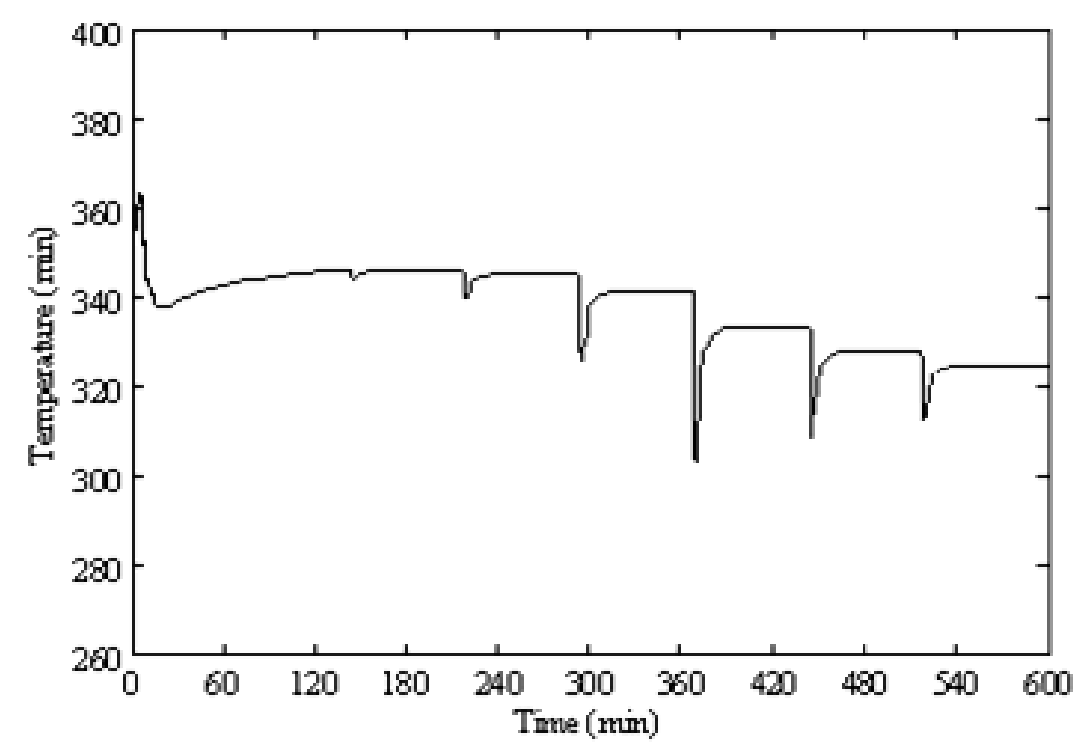

(b)

Fig. 7. The temperature control using NNMPC under the nominal case: (a) the control variable $\left(T_{\mathrm{r}}\right)$ and (b) the manipulated variable $\left(T_{\text {isp }}\right)$. 


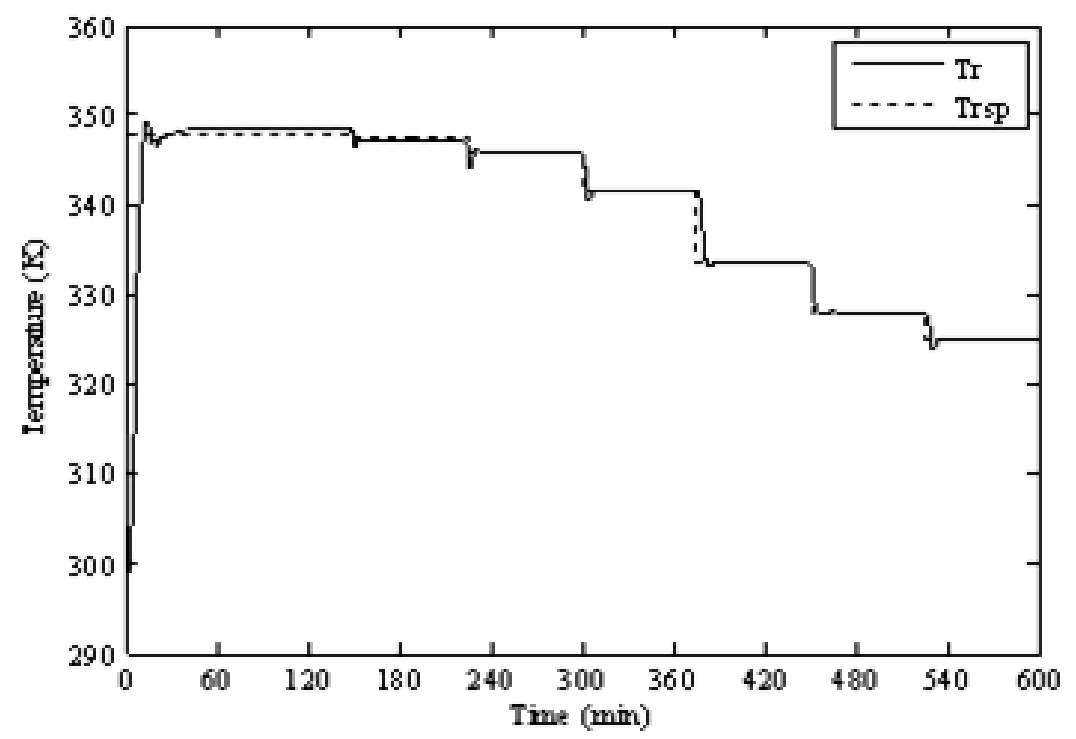

(a)

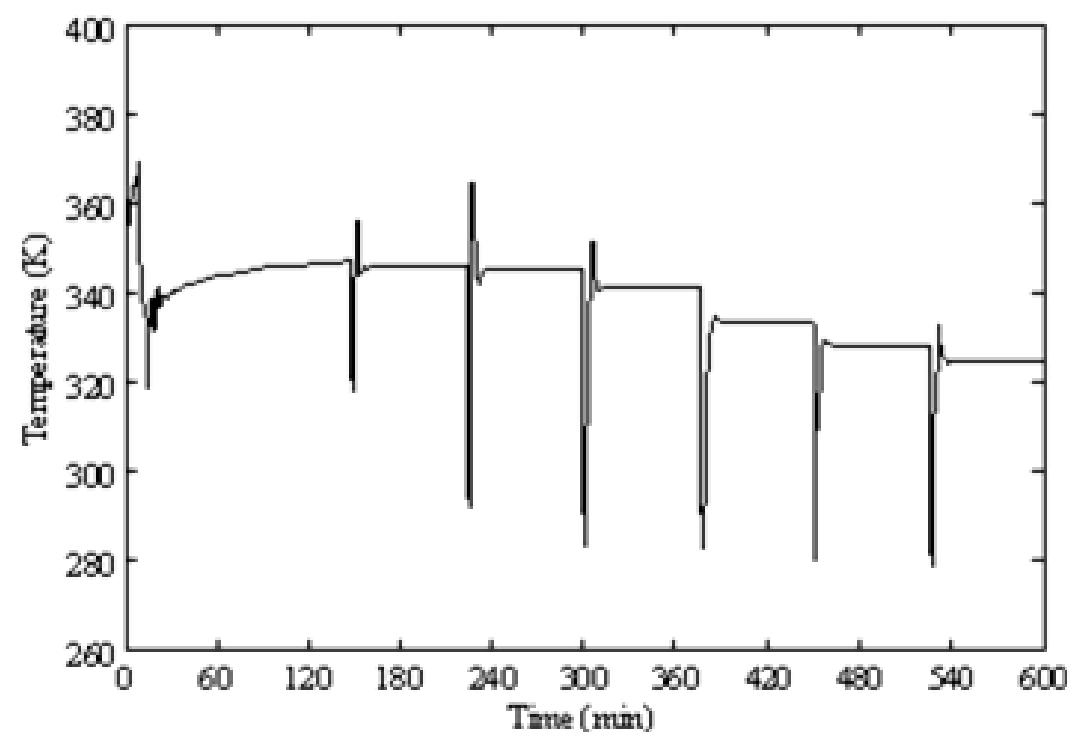

(b)

Fig. 8. The temperature control using NNDIC under the nominal case: (a) the control variable $\left(T_{r}\right)$ and (b) the manipulated variable $\left(T_{\text {isp }}\right)$. 


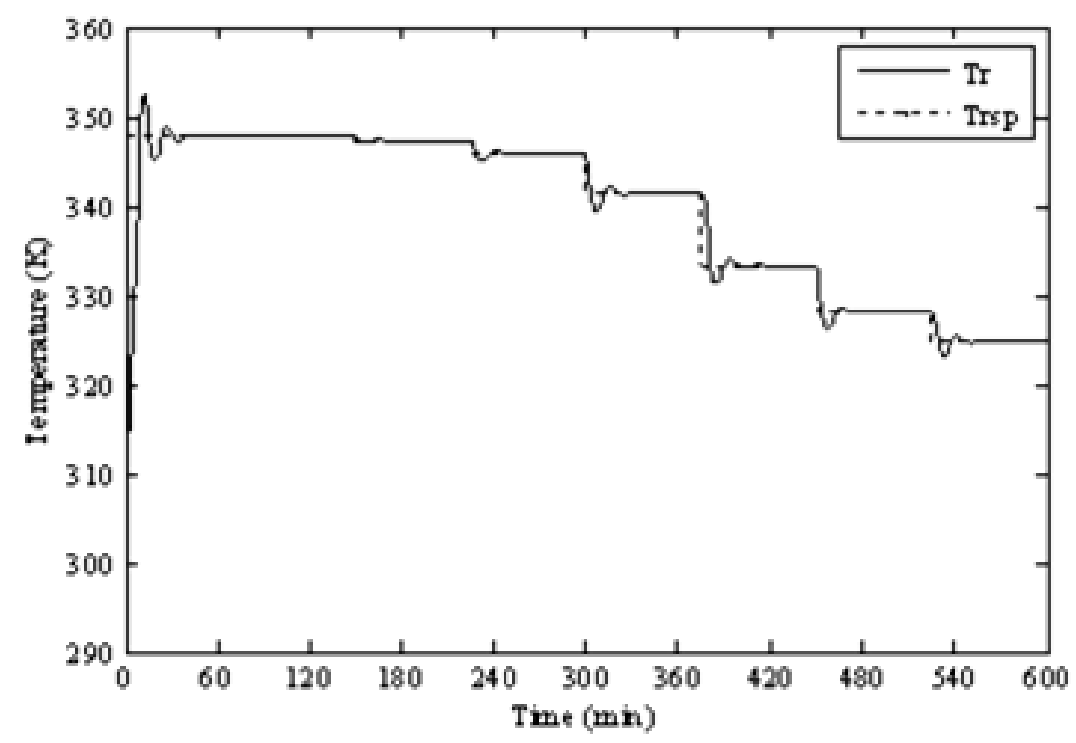

(a)

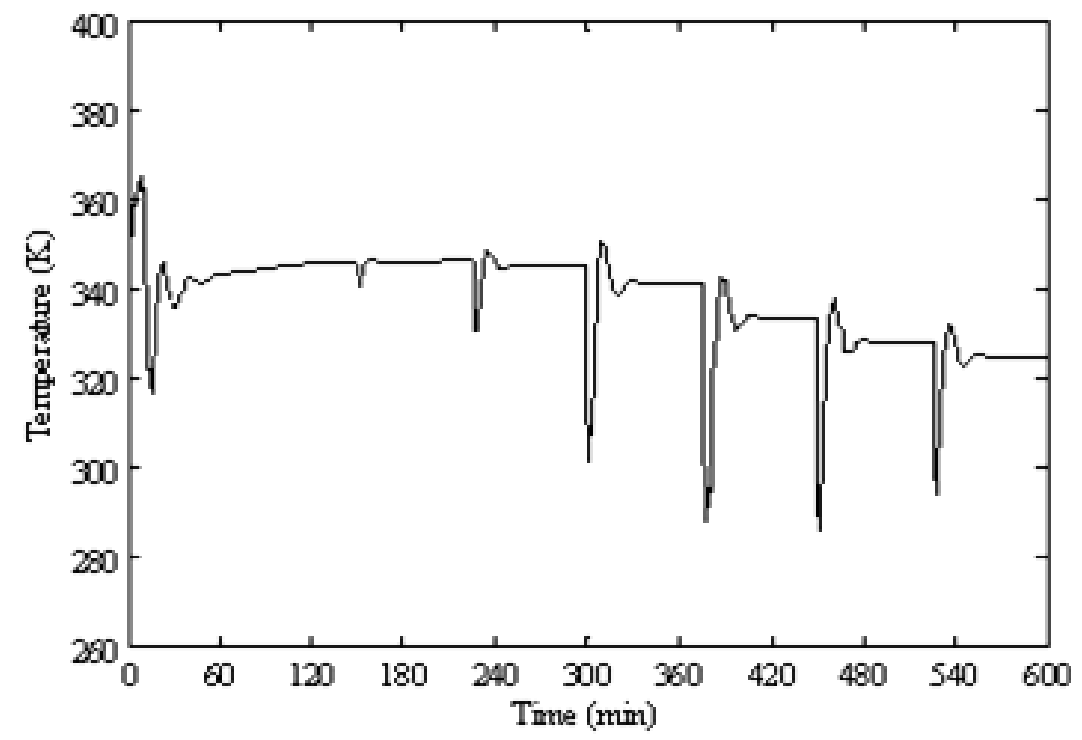

(b)

Fig. 9. The temperature control using PID control under the nominal case: (a) the control variable $\left(T_{\mathrm{r}}\right)$ and (b) the manipulated variable $\left(T_{\text {jsp }}\right)$.

Table 4. Performance indices of NNMPC strategy, PID control strategy and NNDIC strategy for nominal and model mismatch cases.

\begin{tabular}{lccc}
\hline Cases & NNMPC & PID & NNDIC \\
\hline Nominal & 422.0569 & 422.9892 & 422.4777 \\
$+30 \% \mathrm{k}_{1}$ & 421.0025 & 433.2399 & 421.2645 \\
$-30 \% \mathrm{k}_{2}$ & 421.1529 & 424.3498 & 422.0130 \\
$+30 \% \mathrm{k}_{1},-30 \% \mathrm{k}_{2}$ & 421.4568 & 434.5736 & 421.6259 \\
$+30 \% \Delta \mathrm{H}$ & 415.2102 & 433.8296 & 419.5642 \\
$-30 \% \mathrm{U}$ & 435.0598 & 550.6485 & 456.2135 \\
$+30 \% \mathrm{k}_{1},-30 \% \mathrm{k}_{2},+30 \% \Delta \mathrm{H},-30 \% \mathrm{U}$ & 447.0252 & 584.9196 & 462.7851 \\
\hline
\end{tabular}




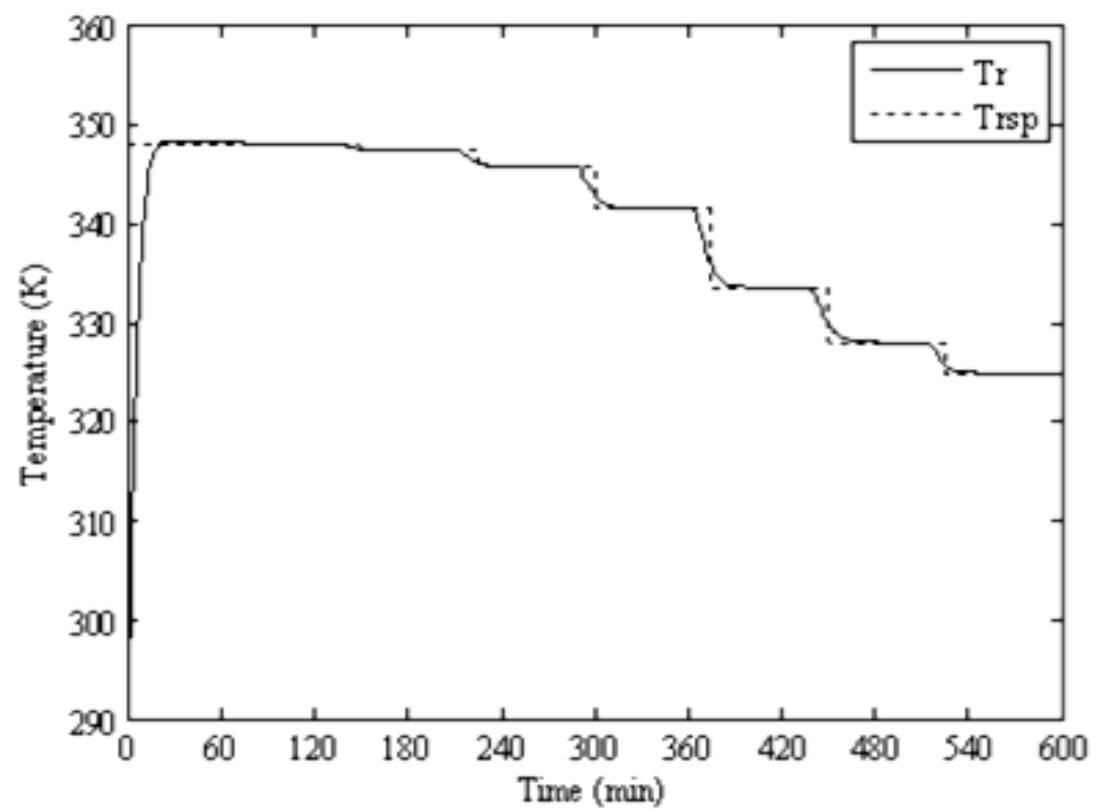

(a)

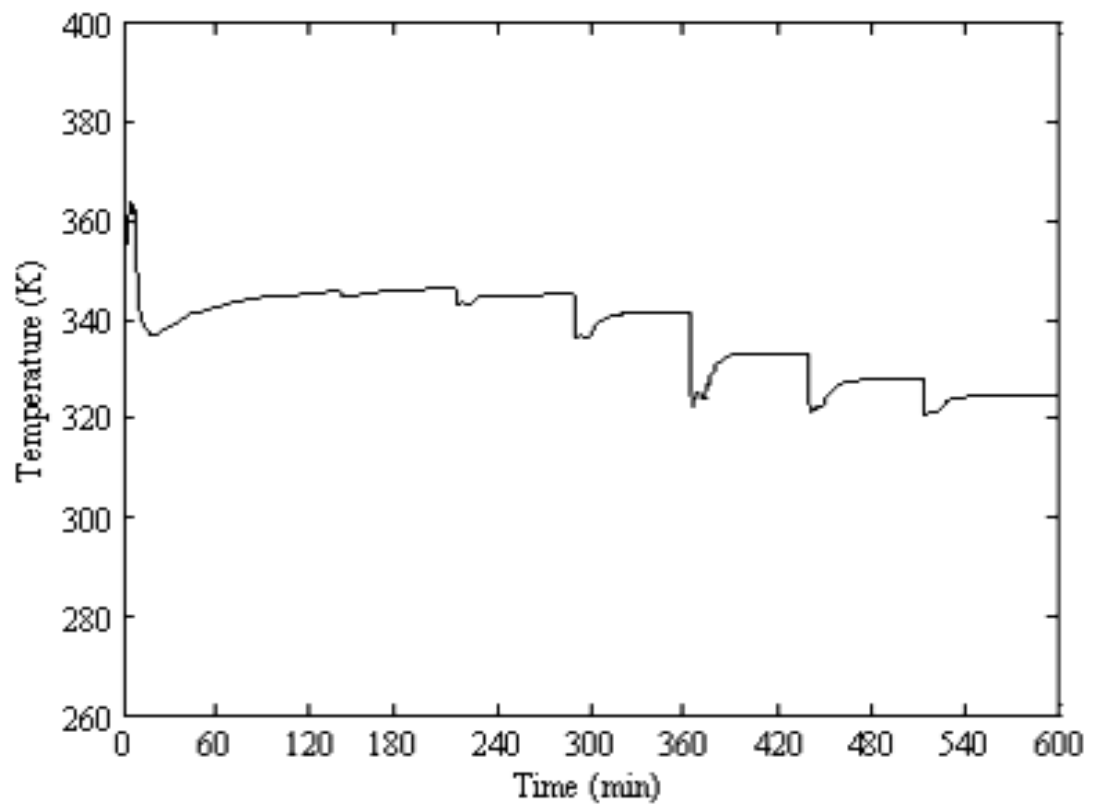

(b)

Fig. 10. The temperature control using NNMPC under the parameter mismatch case $(-30 \% \mathrm{U})$ : (a) the control variable $\left(\mathrm{T}_{\mathrm{r}}\right)$ and $(\mathrm{b})$ the manipulated variable $\left(\mathrm{T}_{\text {isp }}\right)$. 


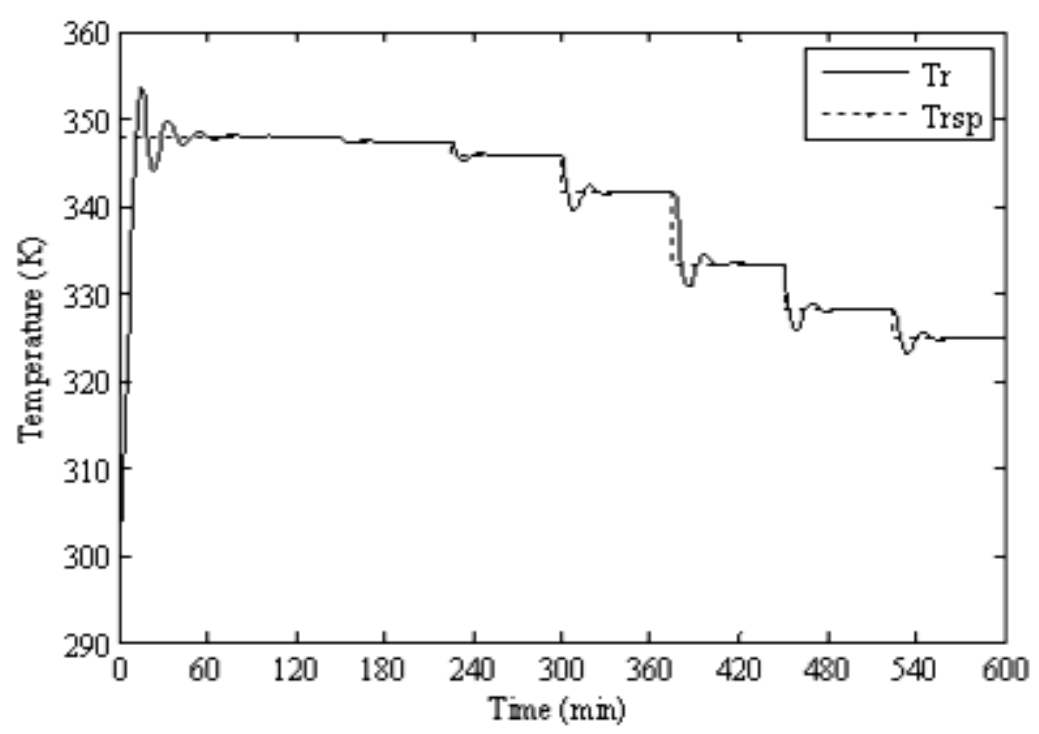

(a)

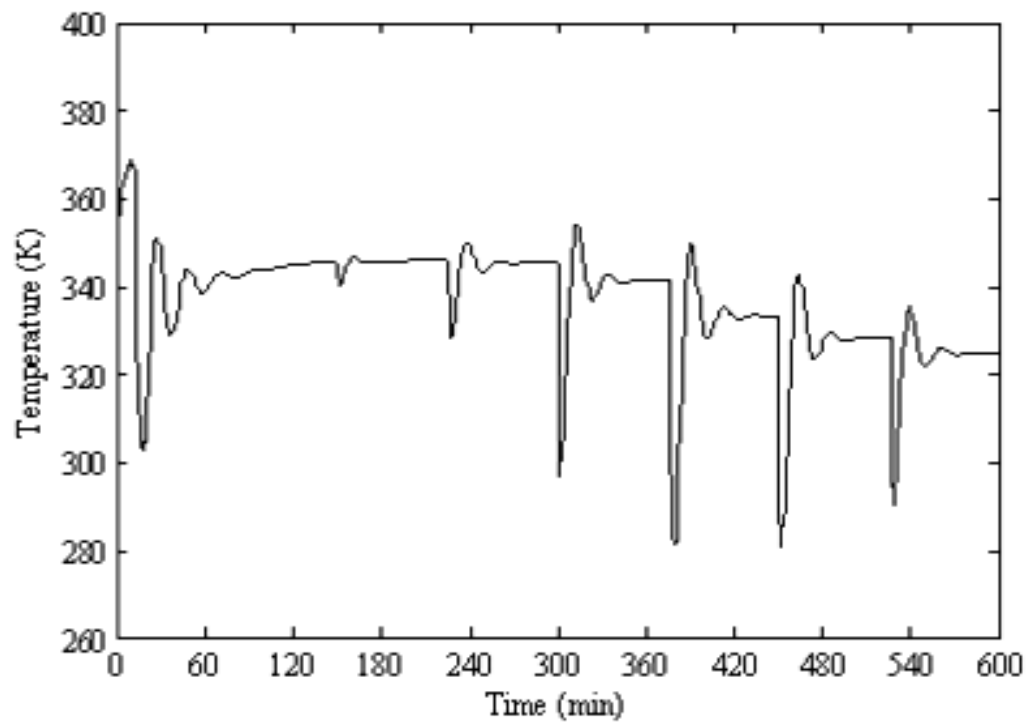

(b)

Fig. 11. The temperature control using PID control under the parameter mismatch case (-30\% U): (a) the control variable $\left(T_{\mathrm{r}}\right)$ and $(\mathrm{b})$ the manipulated variable $\left(T_{\mathrm{jsp}}\right)$. 


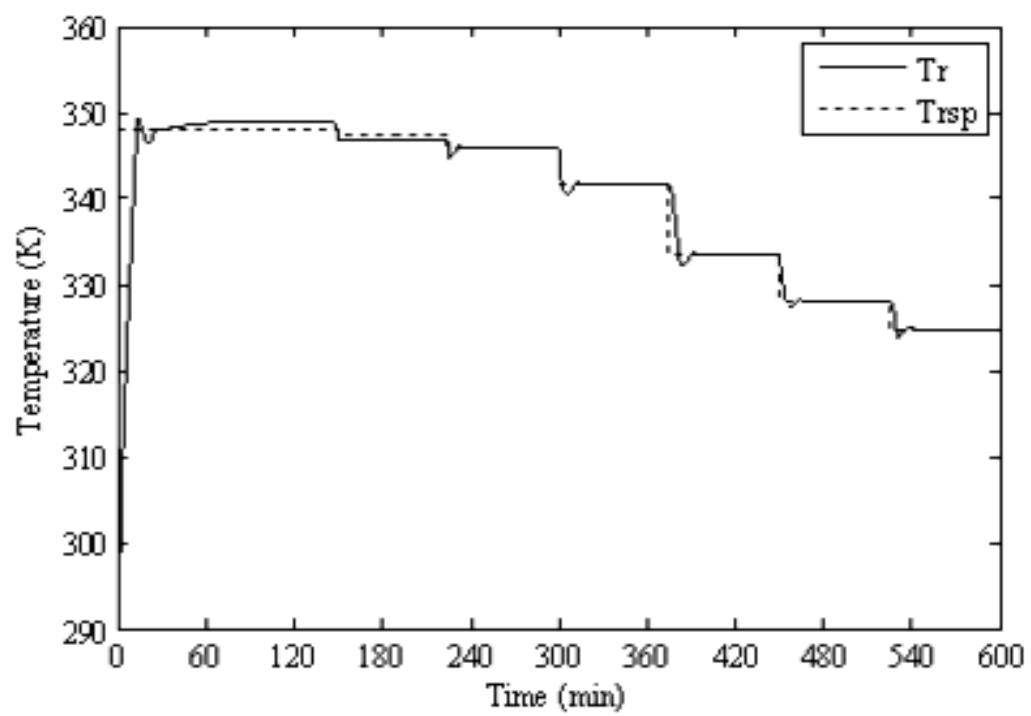

(a)

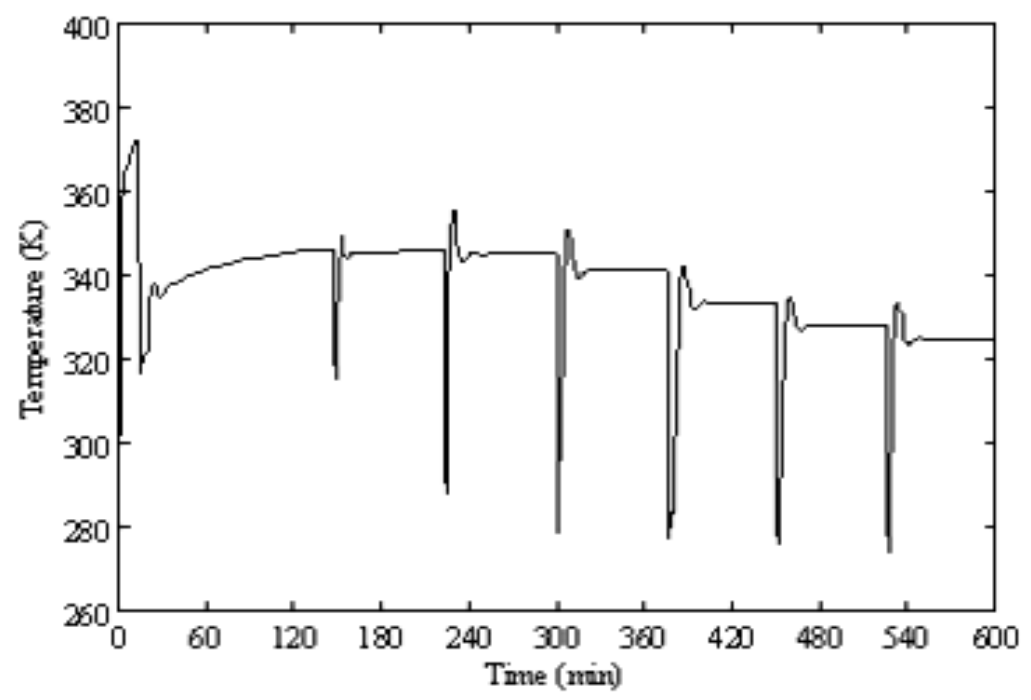

(b)

Fig. 12. The temperature control using NNDIC under the parameter mismatch case $(-30 \% \mathrm{U})$ : (a) the control variable $\left(T_{r}\right)$ and $(b)$ the manipulated variable $\left(T_{\text {jsp }}\right)$

\section{Conclusions}

In this paper, a dynamic optimization, neural network modeling and neural network based controls are proposed to provide effective control performance for the production of methyl methacrylate (MMA) production in an exothermic batch reactor. To control the temperature of the reactor, neural network based control approaches consisting of a neural network direct inverse control (NNDIC) and a neural network based model predictive control (NNMPC) have been formulated. For the neural network modeling, an optimal structure composes of 8 nodes in an input layer, 6 nodes in first hidden layer, 8 nodes in second hidden layer and 3 nodes in an output layer. An obtained neural network forward model is used to predict a dynamics behavior in the NNMPC algorithm. For a neural network inverse model, an optimal structure consists of 8 nodes in an input layer, 4 nodes in first hidden layer, 8 nodes in second hidden layer and a node in an output layer. In a dynamic optimization, a maximum product achieves at the case of 8 intervals. The obtained temperature profile is applied as set points of the process. Robustness tests of three different controls have been studied with respect to changes in operating parameters. Comparisons of control performances among the PID, the NNDIC and the NNMPC indicated that the NNMPC gives the best control performance in the nominal case and plant/model mismatch cases. 


\section{Acknowledgment}

The authors would like to acknowledge the support from the Faculty of Engineering, Burapha University under the contract \# 35/2553.

\section{Nomenclature}

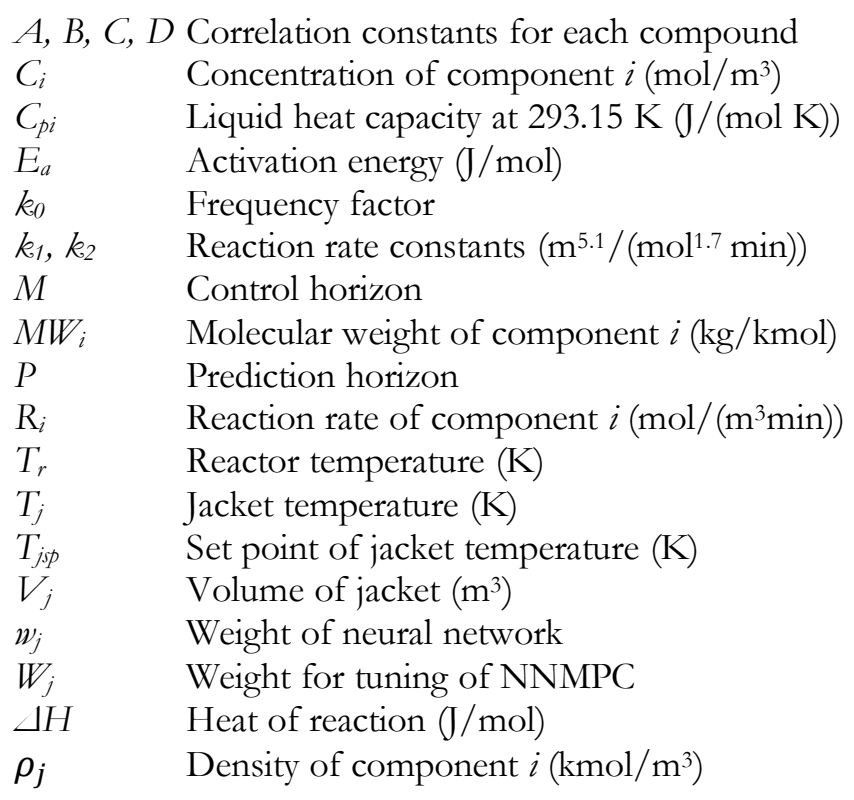

\section{References}

[1] J. J. Spivey, M. R. Gogate, J. R. Zoeller, and R. D. Colberg, "Novel catalysts for the environmentally friendly synthesis of methyl methacrylate," Ind. Eng. Chem. Res., vol. 36, pp. 4600-4608, 1997.

[2] I. M. Mujtaba, N. Aziz, and M. A. Hussain, "Network based modeling and control in batch reactor," Chem Eng Res Des, vol. 84, no. A8, pp. 635-644, 2006.

[3] K. Konakom, P. Kittisupakorn, and I. M. Mujtaba, "Batch control improvement by model predictive control based on multiple reduced-models," Chem Eng J, vol. 145, pp. 129-134, 2008.

[4] N. Aziz, M. A. Hussain, and I. M. Mujtaba, "Optimal control of batch reactors using generic model control (GMC) and neural network," Comput. Aided Chem. Eng., vol. 8, pp. 175-180, 2000.

[5] W. Cho, T. F. Edgar, and J. Lee, "Iterative learning dual-mode control of exothermic batch reactors," Control Eng. Pract., vol. 16, no. 10 pp. 1244-1249, 2008.

[6] B. V. Babu and K. Jyotsna. (2001). Temperature control in an exothermic batch reactor using generic model control and globally linearizing control. [Online]. Available http://www.researchgate.net/publication/228517981 _TEMPERATURE_CONTROL_IN_AN_EXOTHERMIC_BATCH_REACTOR_USING_GENE RIC_MODEL_CONTROL_AND_GLOBALLY_LINEARIZING_CONTROL.

[7] F. Szeifert, T. Chovan, and L. Nagy, "Process dynamics and temperature control of fed-batch reactors," Comput. Chem. Eng., vol. 19, pp. 447-452, Jun. 1995.

[8] C. Alippi and V. Piuri, "Neural modeling of dynamic systems with nonmeasurable state variables," IEEE. Trans. Instr., vol. 6, pp. 1073-1080, 1999.

[9] I. H. Kim, S. Fok, K. Fregene, D. H. Lee, T. S. Oh, and D. W. L. Wang, "Neural network based system identification and controller synthesis for an industrial sewing machine," J Cont. Aut. Sys., vol. 2, no. 1 pp. 83-91, Mar. 2004.

[10] A. P. Loh, K. O. Looi, K. F. Fong, "Neural network modeling and control strategies for a $\mathrm{pH}$ process," J. Proc. Cont., vol. 5, pp. 355-362, Dec. 1995.

[11] R. Murray-Smith, D. Neumerkel, and D. Sbarbaro-Hofer, "Neural network for modeling and control of non-linear dynamic system," in IEEE International Symposium on Intelligent Control, Glasgow, Scotland, 1992, pp. 404-409. 
[12] D. L. Yu and J. B. Gomm, "Implementation of neural network predictive control to a multivariable chemical reactor," Control Eng. Pract., vol. 11, pp. 1315-1323, Nov., 2003.

[13] D. L. Yu, J. B. Gomm, and D. Williams, "Neural model input selection for a MIMO chemical process," Eng. Appl. Artif. Intel., vol. 13, pp. 15-23, Feb., 2000.

[14] P. Kittisupakorn, P. Tangteerasunun, and P. Thitiyasook, "Dynamic neural network modeling for hydrochloric acid recovery process," Korean J. Chem. Eng., vol. 22, no. 6, pp. 813-821, 2005.

[15] H. Rusinowski and W. Stanek, "Neural modeling of steam boilers," Energ. Convers. Manage., vol. 48, pp. 2802-2809, Nov., 2007.

[16] T. Charoenniyom, P. Kittisupakorn, and W. Daosud, "Neural network modelling and optimization of the methyl methacrylate production process for esterification reaction in a batch reactor," in Pure and Applied Chemistry International Conference, Bangkok, 2011, pp. 308-311.

[17] J. Thampasato, P. Kittisupakorn, and W. Daosud, "Neural network modelling and optimization of a batch heating/cooling evaporative crystallization," in The 7th International Conference on Computing and Information Technology, 2011, pp. 196-200.

[18] E. Nueaklong, P. Kittisupakorn, and W. Daosud, "Dynamic and control of heat exchanger system in hard chrome electroplating using neural network," in The 7th International Conference on Computing and Information Technology, 2011, pp. 161-166.

[19] W. Daosud, P. Thitiyasook, A. Arpornwichanop, P. Kittisupakorn, and M.A. Hussain, "Neural network inverse model-based controller for the control of a steel pickling process," Comput. Chem. Eng., vol. 29, pp. 2110-2119, Sep., 2005.

[20] P. Kittisupakorn, P. Thitiyasook, M. A. Hussain, and W. Daosud, "Neural network based model predictive control for a steel pickling process," J. Process Contr., vol. 19, no. 4, pp. 579-590, Apr., 2009.

[21] A. Arpornwichanop and N. Shomchoam, "Control of fed-batch bioreactors by a hybrid on-line optimal control strategy and neural network estimator," Neurocomputing, vol. 72, pp. 2297-2302, Jun., 2009.

[22] M. Grzesik, J. Skrzypek, and M. Witczak, "Kinetic models for esterification of methacrylic acid using n-propanol andisopropanol," Stud. Surf. Sci. Catal., vol. 133, pp. 541-545, 2001.

[23] W. Paengjuntuek, P. Kittisupakorn, and A. Arpornwichanop, "On-line dynamic optimization integrated with generic model control of a batch crystallizer," J. Ind. Eng. Chem., vol. 14, no. 4, pp. 442-448, Jul., 2008.

[24] A. Arpornwichanop, P. Kittisupakorn, and I. M. Mujtaba, "On-line dynamic optimization and control strategy for improving the performance of batch reactors," Chem. Eng. Process, vol. 44 no. 1, pp. 101114, Jan., 2005.

[25] N. Aziz, M. A. Hussain, and I. M. Mujtaba, "Performance of different types of controllers in tracking optimal temperature profiles in batch reactors," Comput. Chem. Eng., vol. 24, pp. 1069-1075, Jul., 2000.

[26] D. M. Himmelblau, "Application of artificial neural networks in chemical engineering," Korean J. Chem. Eng., vol. 17, no. 6, pp. 373-392, 2000.

[27] P. Kittisupakorn, N. Polruksa and W. Daosud, "Neural networks model for the estimation of melt flow rate and density of polymers," in Ninth APCChE Congress and CHEMECA, New Zealand, 2002.

[28] P. Bumroongsri and S. Kheawhom, "MPC for LPV systems based on parameter-dependent Lyapunov function with perturbation on control input strategy," Engineering Journal, vol. 16, no. 2, pp. 61-72, 2012.

[29] P. Bumroongsri and S. Kheawhom, "A polyhedral off-line robust MPC strategy for uncertain polytopic discrete-time systems," Engineering Journal, vol. 16, no. 4, pp. 73-89, 2012. 
